\title{
RISK FACTORS FOR DEATH AMONG UNDER FIVE CHILDREN WITH DIARRHOEA AND BACTERAEMIA IN BANGLADESH
}

KM Shahunja, Tahmeed Ahmed, Md Iqbal Hossain, Md Munirul Islam, Mahmuda Begum Monjory, ASMSB Shahid, Mohammod Jobayer Chisti International Centre for Diarrhoeal Disease Research, Bangladesh (icddr,b). Dhaka, Bangladesh

\section{Background:}

Mortality in diarrhoeal children specifically having bacteraemia had gained less attention in spite of its enormous impact in under five mortality. So we aimed to evaluate risk factors for death among underfive children having both diarrhea and bacteraemia

\section{Method:}

Retrospective analysis we used hospital patients' electronic database of Dhaka Hospital

of 'icddr,b', Bangladesh

We enrolled those were admitted to hospital's in-patient wards and had bacterial growth in their cultured blood samples on admission, between June-2014 and May-2017 - Those who died during hospital stay constituted cases, and those were recovered and discharged considered as controls

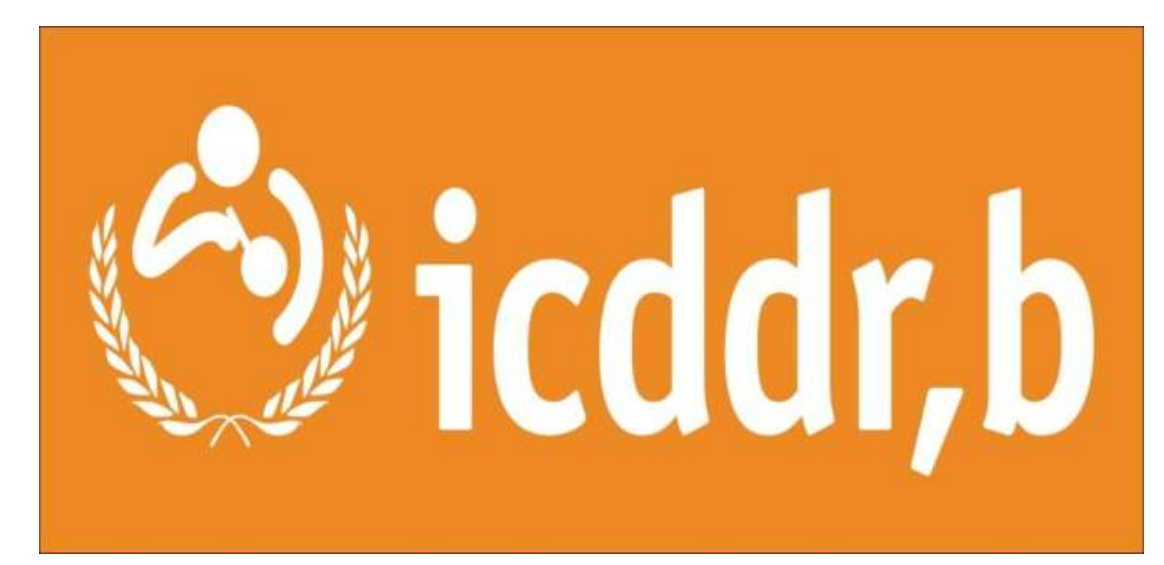

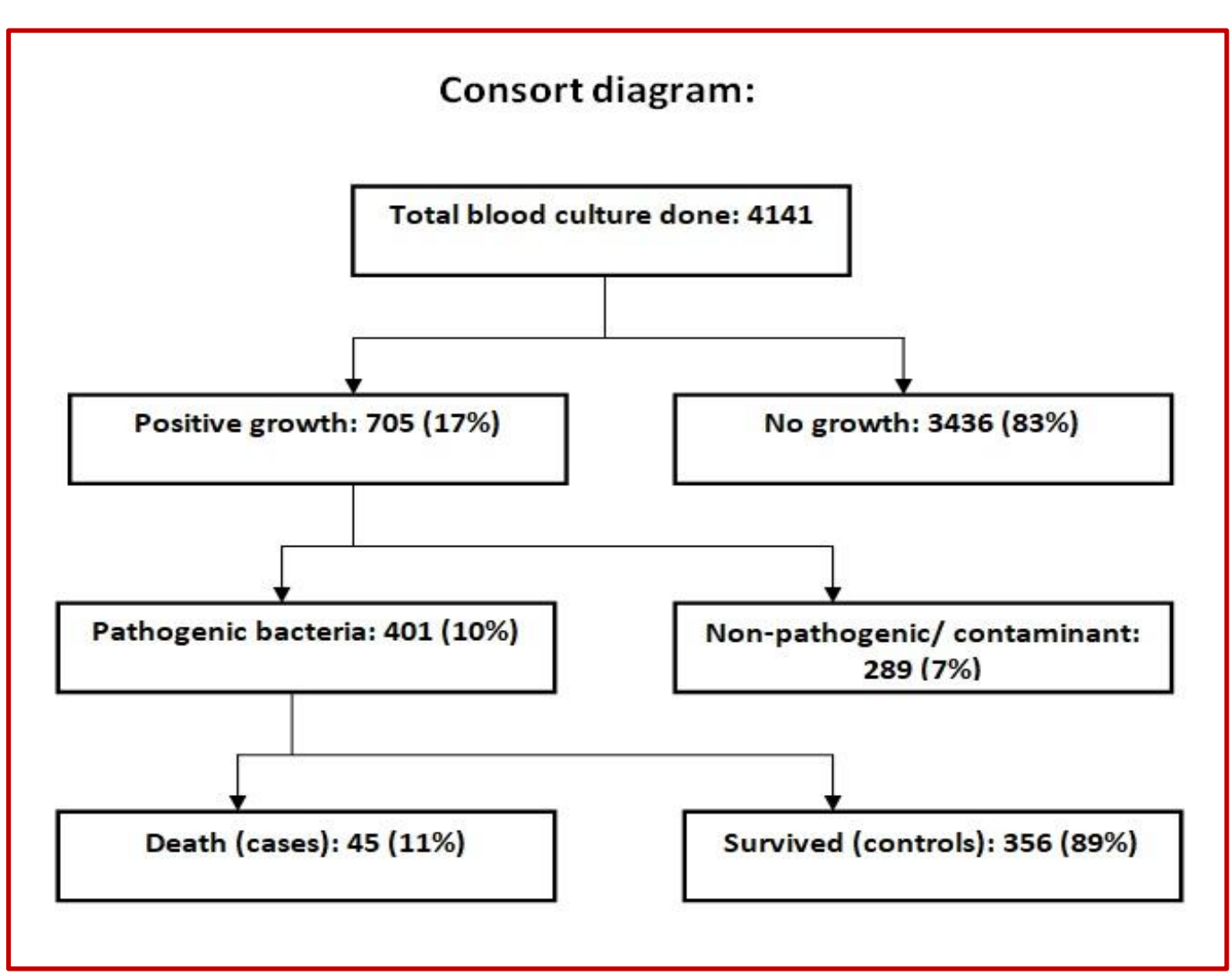

Distribution of bacterial isolates in blood among deaths and survivors

\begin{tabular}{|l|c|c|c|c|}
\hline \multicolumn{1}{|c|}{ Bacteria } & $\begin{array}{c}\text { Deaths } \\
(\mathbf{n = 4 5 )} \\
(\%)\end{array}$ & $\begin{array}{c}\text { Survivor } \\
\mathbf{s}(\mathrm{n=356)} \\
(\%)\end{array}$ & OR (95\% CI) & $\mathbf{p}$ \\
\hline Salmonella typhi & $3(7)$ & $135(38)$ & $0.12(0.35-0.38)$ & 0.001 \\
\hline Staphylococcus sp. & $3(7)$ & $62(17)$ & $0.34(0.10-1.13)$ & 0.103 \\
\hline Pseudomonas sp. & $7(16)$ & $28(8)$ & $2.16(0.88-5.27$ & 0.083 \\
\hline Escherichia coli & $10(22)$ & $17(5)$ & $5.69(2.42-13.39)$ & 0.001 \\
\hline Klebsiella sp. & $8(18)$ & $16(4)$ & $4.59(1.84-11.46)$ & 0.001 \\
\hline Acinetobacter sp. & $2(4)$ & $20(6)$ & $0.78(0.18-3.46)$ & 1.000 \\
\hline Streptococcus sp. & $1(2)$ & $21(5)$ & $0.36(0.05-2.76)$ & 0.491 \\
\hline Salmonella paratyphi & $0(0)$ & $9(2)$ & - & - \\
\hline Campylobacter sp. & $0(0)$ & $9(2)$ & - & - \\
\hline NTS & $1(2)$ & $7(2)$ & $1.13(0.14-9.43)$ & 1.000 \\
\hline Enterococcus sp. & $3(7)$ & $5(1)$ & $5.01(1.16-21.74)$ & 0.049 \\
\hline Shigella sp. & $1(2)$ & $6(2)$ & $1.32(0.16-11.27)$ & 0.568 \\
\hline
\end{tabular}

Organism specific antibiotics resistance pattern

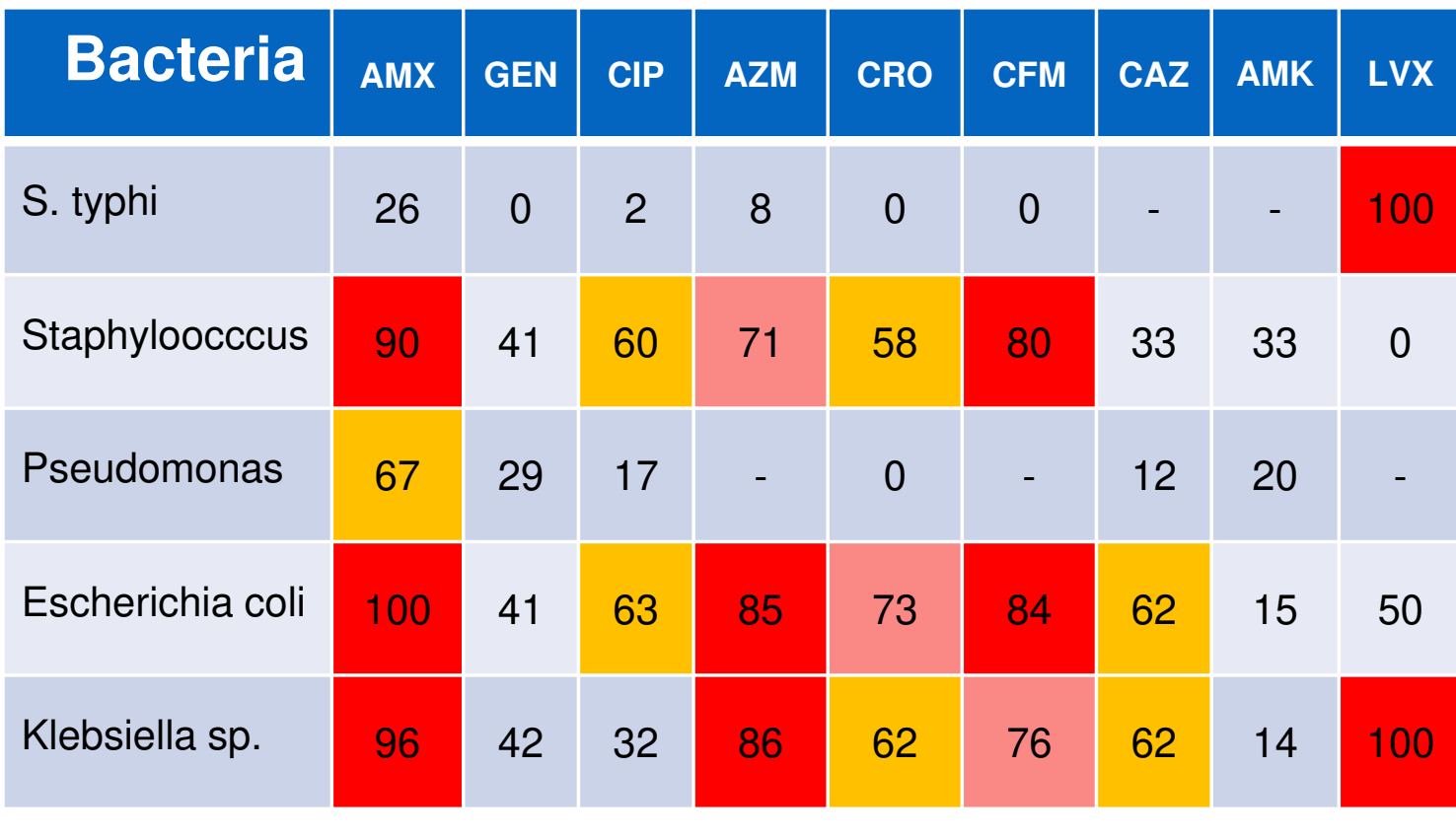

AMX = ampicillin, GEN = gentamycin, $\mathrm{CIP}=$ ciprofloxacin; $\mathrm{CRO}=$ ceftriaxone, $\mathrm{CAZ}=$ ceftazidime, AMK = amikacin, AZM = azithromycin; CFM= cefixime; LVX= levofloxacin; NTS $=$ Non-typhoidal salmonell

Factors associated with deaths (logistic regression)

\begin{tabular}{|l|l|l|l|}
\hline \multicolumn{1}{|c|}{ Variables } & OR & $95 \%$ Cl & P \\
\hline Age in months & 1.04 & $0.99-1.10$ & 0.133 \\
\hline Pneumonia & 2.88 & $0.93-8.90$ & 0.066 \\
\hline Sepsis & 4.74 & $1.53-14.72$ & 0.007 \\
\hline Hypoxemia & 3.66 & $1.24-10.74$ & 0.018 \\
\hline Convulsion & 0.77 & $0.25-2.38$ & 0.647 \\
\hline Severe malnutrition & 1.04 & $0.32-3.37$ & 0.948 \\
\hline Sensitive Abx received & 0.43 & $0.16-1.15$ & 0.094 \\
\hline Abnormal WBC count & 1.45 & $0.43-4.90$ & 0.548 \\
\hline Hyperkalemia & 1.47 & $0.45-4.78$ & 0.523 \\
\hline Acute kidney injury & 1.00 & $0.32-3.14$ & 0.998 \\
\hline Hypermagnesemia & 0.46 & $0.15-1.43$ & 0.181 \\
\hline
\end{tabular}

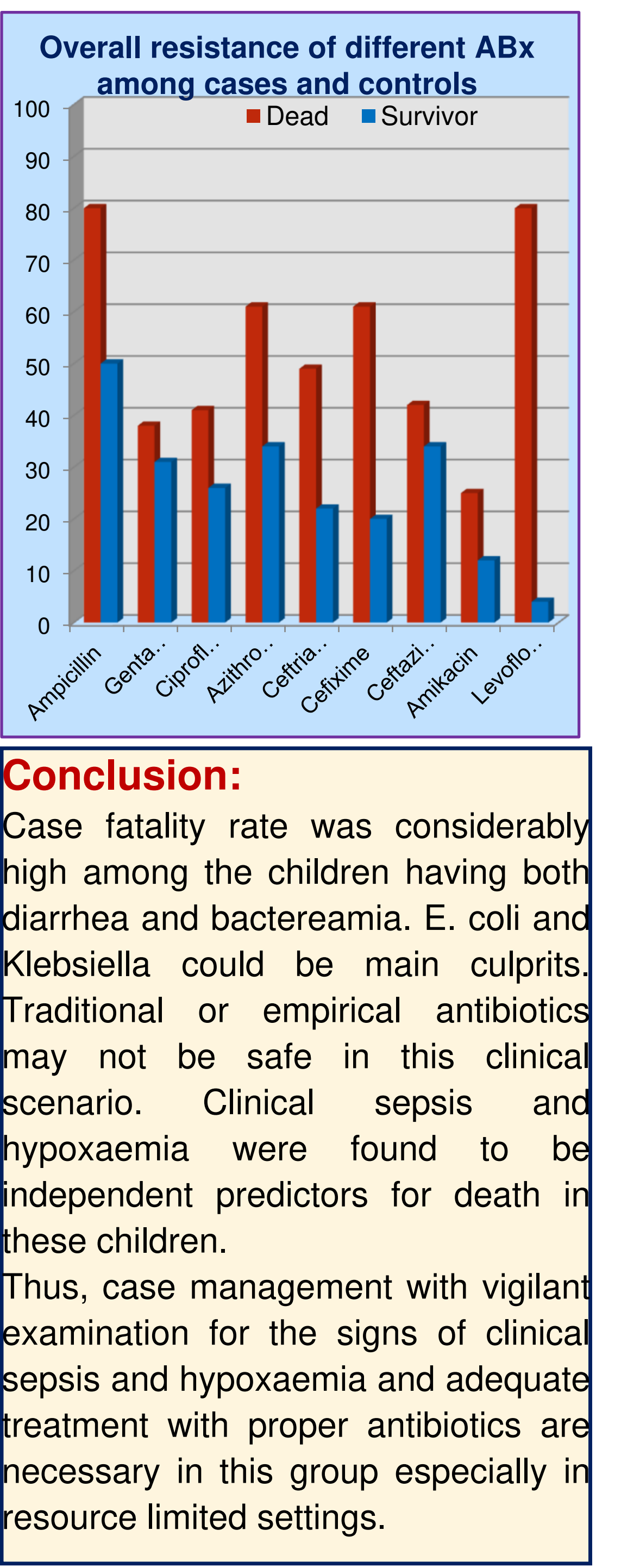

